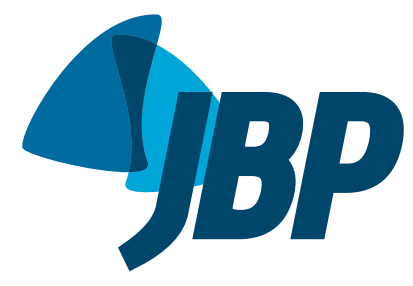

\title{
Assessment of fatigue using the Identity- Consequence Fatigue Scale in patients with lung cancer
}

\author{
Ingrid Correia Nogueira',2, Amanda Souza Araújo ${ }^{1,2}$, Maria Tereza Morano ${ }^{1,2,3}$, \\ Antonio George Cavalcante ${ }^{1}$, Pedro Felipe de Bruin ${ }^{1}$, Johana Susan Paddison ${ }^{4}$, \\ Guilherme Pinheiro da Silva ${ }^{1,3}$, Eanes Delgado Pereira ${ }^{1,2}$
}

1. Universidade Federal do Ceará - UFC Fortaleza (CE) Brasil.

2. Hospital de Messejana Dr. Carlos Alberto Studart Gomes, Fortaleza (CE) Brasil.

3. Universidade de Fortaleza - UNIFOR Fortaleza (CE) Brasil.

4. Wellington Regional Hospital, Newtown, Wellington, New Zealand.

Submitted: 18 February 2016.

Accepted: 14 July 2016

Study carried out in the Universidade Federal do Ceará, Fortaleza (CE) Brasil.

\begin{abstract}
Objective: To evaluate the properties of the Identity-Consequence Fatigue Scale (ICFS) in patients with lung cancer (LC), assessing the intensity of fatigue and associated factors. Methods: This was a cross-sectional study involving LC patients, treated at a teaching hospital in Brazil, who completed the ICFS. Patients with chronic heart disease (CHD) and healthy controls, matched for age and gender, also completed the scale. Initially, a Brazilian Portuguese-language version of the ICFS was administered to 50 LC patients by two independent interviewers; to test for reproducibility, it was readministered to those same patients. At baseline, the LC patients were submitted to spirometry and the six-minute walk test, as well as completing the Epworth Sleepiness Scale (ESS), Hospital Anxiety and Depression Scale (HADS), Medical Outcomes Study 36-item Short-Form Health Survey (SF-36), and Fatigue Severity Scale (FSS). Inflammatory status was assessed by blood C-reactive protein (CRP) levels. To validate the ICFS, we assessed the correlations of its scores with those variables. Results: The sample comprised 50 patients in each group (LC, CHD, and control). In the LC group, the intraclass correlation coefficients for intra-rater and inter-rater reliability regarding ICFS summary variables ranged from 0.94 to 0.76 and from 0.94 to 0.79 , respectively. The ICFS presented excellent internal consistency, and Bland-Altman plots showed good test-retest reliability. The ICFS correlated significantly with FSS, HADS, and SF-36 scores, as well as with CRP levels. Mean ICFS scores in the LC group differed significantly from those in the CHD and control groups. Conclusions: The ICFS is a valid, reliable instrument for evaluating LC patients, in whom depression, quality of life, and CRP levels seem to be significantly associated with fatigue.
\end{abstract}

Keywords: Fatigue; Lung neoplasms; Symptom assessment.

\section{INTRODUCTION}

Fatigue is a subjective complaint of patients with various chronic illnesses and can affect work performance and activities of daily living, as well as social and family responsibilities. ${ }^{(1)}$ Cancer-related fatigue is reportedly in the range of $70-80 \% .^{(1-3)}$ The most severe fatigue is reported among lung cancer (LC) patients and persists for several months or years after treatment completion, having a great negative impact on the quality of life of those patients. ${ }^{(4-7)}$

The pathogenesis of cancer-related fatigue is poorly understood. In attempts to explain fatigue, models have been developed based on both physiological and psychological aspects. The mechanisms involve effects of cancer or of its treatment on the central nervous system, muscle energy metabolism, sleep/circadian rhythms, ${ }^{(8,9)}$ mediators of inflammation, ${ }^{(10)}$ stress, ${ }^{(10)}$ immune activation, ${ }^{(11)}$ and hormonal changes related to effects on the hypothalamic-pituitary axis. ${ }^{(12-14)}$ Immune activation has been associated with fatigue and depression in patients with cancer or other chronic diseases. ${ }^{(15,16)}$ Therefore, a better understanding of LC-related fatigue and its correlation with biomarkers, physical function, and psychological parameters is important to enable more personalized interventions.

Fatigue is also one of the most commonly reported symptoms by patients with chronic heart disease (CHD). Causes of fatigue in heart failure include low cardiac output, poor tissue perfusion, muscle metabolic abnormalities, autonomic nervous system abnormalities, deconditioning effects, and endothelial dysfunction. ${ }^{(17,18)}$

Fatigue has been most commonly assessed by self-report questionnaires. ${ }^{(2-5)}$ The Identity-Consequence Fatigue Scale (ICFS) is a validated comprehensive questionnaire that identifies the energy levels of patients and is appropriate to identify both mental and behavioral consequences of cancer-related fatigue. ${ }^{(19,20)}$ The objective of this study was to evaluate the measurement properties of the ICFS, as well as the intensity of fatigue and the associated factors, in LC patients. To our knowledge, this is the first

Correspondence to:

Eanes Delgado Barros Pereira. Rua Professor Costa Mendes, 1608, $4^{\circ}$ andar, CEP 60020-181, Fortaleza, CE, Brasil.

Tel.: 5585 3366-8054. Fax: 5585 3366-8054. E-mail: eanes@fortalnet.com.br

Financial support: This study received partial financial support from the Conselho Nacional de Desenvolvimento Cientifico e Tecnológico ICNPq, Brazilian National Council

for Scientific and Technological Development). 
study to evaluate fatigue using the ICFS in LC patients. Because ICFS is a generic fatigue questionnaire, it allows for comparisons to be made among different patient populations.

\section{METHODS}

This was a cross-sectional study involving 50 consecutive patients previously diagnosed with non-small cell LC (LC group) and referred to an outpatient clinic at a teaching hospital in the city of Fortaleza, Brazil, for staging and potential surgical treatment. Patients who were incapable of understanding the scale were excluded, as were those who had neurologic, vascular, or musculoskeletal diseases that limited their ability to perform the six-minute walk test (6MWT). In addition, two other groups, matched for age and gender, were studied for comparison: 50 patients with CHD recruited from the cardiology outpatient clinic in the same teaching hospital (CHD group); and 50 healthy volunteers from a local community senior center (control group).

All LC cancer participants were initially assessed in order to determine relevant demographic and clinical parameters. LC staging was obtained from the medical records of the patients. All LC patients underwent spirometry, were submitted to the 6MWT, completed questionnaires/scales (anxiety and depression, fatigue, daytime somnolence, and health-related quality of life), and had their serum C-reactive protein (CRP) levels measured. Specific questionnaires were completed in a face-to-face interview by two medical investigators. A metabolic equivalent of CRP was established in order to determine the validity of ICFS, because we hypothesized that fatigue was associated with inflammation. The participants in the CHD and control groups completed the ICFS once only.

\section{Research tool}

The ICFS is a 31 -item self-report tool that assesses five domains of fatigue (feelings of fatigue, feelings of vigor, impacts on concentration, impacts on energy, and impacts on daily activities) and provides two summary scores: fatigue experiences and fatigue impacts. ${ }^{(19)}$

The "fatigue experiences" score is the average of "feelings of fatigue," "feelings of vigor," and "impacts on concentration" subscale scores. The "fatigue impacts" score is the average of "impacts on energy" and "impacts on daily activities" subscale scores. For the items in the "feelings of fatigue," "feelings of vigor," "impacts on energy," and "impacts on concentration" domains, the anchors are "not at all" (score = 0); and "almost never," "some of the time," "fairly often," "very often," and "all of the time" (score = 5). For the items in the "daily activity" domain, the anchors are "not at all" (score = 0); and "only occasionally," "some of the time but less than usual," "nearly as often as usual," and "as often as usual" (score = 4). For two items in the "impacts on energy" subscale ("I have achieved very little with the day" and "I lack the energy to do things that I normally do"), the scores are rated as follows: 0
= "I strongly agree"; 1 = "I agree"; 2 = "neutral"; 3 = "I disagree"; and 4 = "I strongly disagree." The scores are reported as a percentage of the maximum possible score available for each participant. In this study we used the Brazilian-Portuguese version of the ICFS.

\section{Translation process}

First, the English-language version of the ICFS was independently translated into Brazilian Portuguese by two of the investigators. The two translations were compared until a consensus version was agreed upon. That version was administered to a small sample of five patients with LC in order to evaluate clarity and to ensure that no terms or situations in the questionnaire were considered obscure or difficult to understand. This Brazilian Portuguese-language version was then back-translated into English by a translator who had no prior knowledge of the original scale. The author of the original scale assessed the back-translation, which was discussed with the investigators, and a final version was then obtained. The final version (Appendix) was administered to the participants in the present study. The Appendix is available online at http://jornaldepneumologia.com.br/detalhe_anexo. asp?id $=50$

\section{Measurements}

In order to test the inter-rater reliability of the Brazilian Portuguese-language version of the ICFS, the instrument was administered to the LC patients twice by two observers, 30 minutes apart, during the first visit (V1). The second visit (V2) occurred 7 days after $\mathrm{V} 1$, and the ICFS was again administered to the same patients by only one of the observers in order to test intra-rater reliability. We chose a 7-day interval because it was more practical for the participants who lived outside the city of Fortaleza and for those who had started receiving chemotherapy. A 7-day interval between visits has also been used in other intra-observer reliability studies. ${ }^{(21)}$ All other assessments were carried out at V1.

The Fatigue Severity Scale (FSS) ${ }^{(22)}$ is a seven-point Likert scale in which 1 means "I strongly disagree," and 7 means "I strongly agree." Higher scores indicate more severe fatigue. In the present study, we used the Portuguese-language version of the FSS validated for use in Brazil. (23)

Symptoms of depression and anxiety states were assessed using the Hospital Anxiety and Depression Scale (HADS). This scale consists of 14 items, of which 7 focus on the assessment of anxiety (HADS-A subscale), and 7 focus on the assessment of depression (HADS-D subscale). Each item can be scored from 0 to 3, the maximum score on each subscale being 21 points. This scale was selected because it was specifically developed to assess anxiety and depression in medically ill patients; therefore, it excludes items that are related to somatic symptoms. ${ }^{(24)}$ We used the Portuguese-language version of the HADS validated for use in Brazil.(25)

The Medical Outcomes Study 36-item Short-Form Health Survey (SF-36) is a patient-reported survey 
of health status. It consists of eight scaled scores which are the weighted sums of the questions in each section. Each scale is directly transformed into a 0 -100 scale on the assumption that each question carries an equal weight. Lower scores indicate more disability. The SF-36 has been translated and adapted for use in Brazil. (26)

The Epworth Sleepiness Scale (ESS) is a simple and reliable instrument that has been widely used in order to measure daytime sleepiness; we used the ESS version that had been translated to Portuguese and adapted for use in Brazil.(27) The subjects are required to rate their likelihood of falling asleep on a scale of increasing probability (from 0 to 3 ) for eight different situations in which most people find themselves during their activities of daily living. The scores for the eight questions are added together to obtain a single number. ${ }^{(28)}$

Spirometry was performed in accordance with Miller et al. (29) Measurements included FEV ${ }_{1}, F$ C , and the $\mathrm{FEV}_{1}$ / FVC ratio. The results were compared with reference values established by Pereira et al. ${ }^{(30)}$

The 6MWT is a simple and practical standardized test for the evaluation of exercise capacity. The six-minute walk distance (6MWD) is defined as the distance a patient can quickly walk on a flat, hard surface in a period of six minutes. ${ }^{(31)}$ The test was carried out indoors along a flat, straight, 30-m corridor. Patients were asked to walk at their fastest pace from one end of the corridor to the other end as many times as possible. The 6MWD was then measured.

\section{Statistics}

Data were statistically analyzed with the Statistical Package for the Social Sciences, version 17.0 (SPSS Inc., Chicago, IL, USA). We used descriptive analysis and frequencies in order to assess the characteristics of the sample. Kruskal-Wallis $\mathrm{H}$ test was used in order to compare the fatigue scores in the three groups. We used the intraclass correlation coefficient (ICC) for the analysis of reproducibility of the application and reapplication of the ICFS (V1 vs. V2). The Wilcoxon test was used in order to compare the scores obtained from the administration of the ICFS by the same observer in V1 and V2. Bland-Altman plots were used in order to improve the visualization of the test-retest reliability obtained from the various administrations of the ICFS. The ICFS was tested for internal consistency by Cronbach's alpha coefficient. In order to validate the ICFS, we used Spearman's correlation test to assess the strength of the correlations between its scores and those obtained on the FSS, HADS, SF-36, and ESS, as well as the 6MWD, spirometry values, and CRP levels. Bonferroni correction was used for multiple comparisons to alter the $p$ value to a more stringent value in order to reduce the likelihood of a type I error. The level of significance was set at $5 \%$. The sample size (50 subjects) was calculated on the basis of the hypothesis of a moderate correlation ( $r=$ 0.5 ) between the degree of fatigue measured by the
ICFS and that measured by other instruments. That level was set at two-sided $a=0.05$ and $\beta=0.20$.

\section{Ethical aspects}

This study was conducted in accordance with Brazilian National Health Council Resolution 196/96, which established ethical principles for human research, and was approved by the local research ethics committee. All patients gave written informed consent prior to their inclusion in the study.

\section{RESULTS}

The study sample comprised 150 patients, 50 in each group (LC, CHD, and control). The major characteristics of the patients in the LC group are summarized in Table 1. A Kruskal-Wallis $\mathrm{H}$ test showed that there was a statistically significant difference in the "fatigue experiences" scores among the three groups $-x^{2}(2)$ $=23.63 ; p=0.001-$ with a mean rank score of 80.2 in the LC group, 92.2 in the CHD group, and 51.6 in the control group (Table 2). A post hoc test showed that there was no difference between the LC and CHD groups regarding the ICFS summary variable "fatigue experiences"; both groups presented with a higher level of fatigue when compared with the control group. There was a progressive increase in the mean rank of the ICFS summary variable "fatigue impacts" scores $\left(X^{2}(2)=41.74 ; p=0.001\right)$. A post hoc test showed that there was a significant difference when the control group was compared with the LC and the CHD groups ( $p<0.001$ for both), and when the LC group was compared with the CHD group ( $p<0.001$ ). No differences in the ICFS summary variables "fatigue experiences" and "fatigue impacts" were observed in regard to gender, age ( $\leq 65$ years vs. > 65 years), LC staging (stages I/II vs. III/IV), or chemotherapy.

There were no significant differences between the ICFS summary variables "fatigue experiences" and "fatigue impacts" scores obtained by the same observer in different visits $(\mathrm{V} 1=30.9 \pm 18.4 ; \mathrm{V} 2=31.8 \pm$ $17.1 ; \mathrm{p}=0.8 ;$ and $\mathrm{V} 1=28.1 \pm 15.0 ; \mathrm{V} 2=25.3 \pm$ $12.9 ; p=0.3$; respectively). The ICCs for intra-rater reliability (V1 vs. V2) regarding the same summary variables were 0.94 (95\% CI: $0.90-0.97)$ and 0.76 (95\% CI: 0.57-0.86), respectively. Neither were there significant differences between the two observers of the study for the same summary variables scores (30.9 \pm 18.4 vs. $32.5 \pm 19.8 ; p=0.6 ;$ and $28.1 \pm 15.0$ vs. $28.2 \pm 10.0 ; p=1.0$; respectively). The ICCs for inter-rater reliability on the ICFS summary variables "fatigue experiences" and "fatigue impacts" were 0.94 (95\% CI: 0.90-0.96) and 0.79 (95\% CI: 0.64-0.88), respectively. Excellent inter-rater and intra-rater reliability were also identified in the Bland-Altman plots (Figures 1 and 2). The Cronbach's alpha coefficient for the ICFS was 0.88 (95\% CI: 0.82-0.92), indicating excellent internal consistency.

There were significant correlations of the FSS scores with the ICFS summary variables "fatigue experiences" 
and "fatigue impacts" scores $(r=0.60$ and $r=0.52$, respectively). Anxiety and depression scales were significantly correlated with the summary variables

Table 1. Characteristics of the patients with lung cancer in the study $(\mathrm{N}=50){ }^{\text {a }}$

\begin{tabular}{|c|c|}
\hline Variable & Result \\
\hline Age, years $^{b}$ & $60 \pm 12.2$ \\
\hline \multicolumn{2}{|l|}{ Gender } \\
\hline Male & $27(54)$ \\
\hline Female & $23(46)$ \\
\hline \multicolumn{2}{|l|}{ Cancer stage $^{\mathrm{b}}$} \\
\hline | or || & $24(48)$ \\
\hline III or IV & $26(52)$ \\
\hline \multicolumn{2}{|l|}{ Chemotherapyc } \\
\hline Yes & $6(12)$ \\
\hline No & $44(88)$ \\
\hline $\mathrm{FEV}_{1}, \%$ of predicted ${ }^{\mathrm{b}}$ & $86.3 \pm 19.8$ \\
\hline FVC, $\%$ of predicted ${ }^{\mathrm{b}}$ & $86.9 \pm 17.8$ \\
\hline 6MWD, $\mathrm{m}^{\mathrm{b}}$ & $478.4 \pm 104.6$ \\
\hline $\mathrm{BMI}, \mathrm{kg} / \mathrm{m} 2^{\mathrm{b}}$ & $25.9 \pm 3.5$ \\
\hline \multicolumn{2}{|l|}{ ICFS $^{d}$} \\
\hline Feelings of fatigue & $32(12-44)$ \\
\hline Feelings of vigor & $45(5-60)$ \\
\hline Impacts on energy & $35.7(28.5-50.0)$ \\
\hline Impacts on concentration & $22(8-40)$ \\
\hline Impacts on daily activities & $14.3(1.0-27.0)$ \\
\hline \multicolumn{2}{|l|}{ ICFS summary variable } \\
\hline Fatigue impacts ${ }^{d}$ & $24.3(17.6-38.0)$ \\
\hline Fatigue experiences ${ }^{b}$ & $31.9 \pm 18.6$ \\
\hline Epworth Sleepiness Scale ${ }^{b}$ & $7.1 \pm 3.8$ \\
\hline SF-36 MCS & $47.7 \pm 13.3$ \\
\hline SF-36 PCS & $45.6 \pm 8.4$ \\
\hline Fatigue Severity Scale $^{d}$ & $23(12-33)$ \\
\hline HADS-A ${ }^{d}$ & $5(3-8)$ \\
\hline HADS-D ${ }^{d}$ & $4.5(2.0-7.0)$ \\
\hline CRP, $\mathrm{mg} / \mathrm{L}^{\mathrm{d}}$ & $2.9(1.1-6.1)$ \\
\hline $\begin{array}{l}\text { 6MWD: six-minute walk dis } \\
\text { Consequence Fatigue Sc } \\
\text { Outcomes Study } 36 \text {-item Shc } \\
\text { MCS: mental component SL } \\
\text { component summary; HADS- } \\
\text { Depression Scale-anxiety sub } \\
\text { Anxiety and Depression Sca } \\
\text { and CRP: C-reactive protein. } \\
\text { as } \mathrm{n}(\%) \text {, except otherwise } \\
\text { expressed as mean } \pm \mathrm{SD} \text {. 'c } \\
\text { those patients were being e } \\
\text { chemotherapy treatment. }{ }^{c} \mathrm{~V} \\
\text { median (interquartile range). }\end{array}$ & $\begin{array}{l}\text { ICFS: Identity- } \\
\text { SF-36: Medical } \\
\text { m Health Survey; } \\
\text { y; PCS: physical } \\
\text { spital Anxiety and } \\
\text { HADS-D: Hospital } \\
\text { ression subscale; } \\
\text { es are expressed } \\
\text { ated. bValues are } \\
\text { assessment day, } \\
\text { ed for a potential } \\
\text { are expressed as }\end{array}$ \\
\hline
\end{tabular}

"fatigue experiences" ( $r=0.43 ; p=<0.01 ;$ and $r=$ $0.60 ; \mathrm{p}=<0.01$; respectively) and "fatigue impacts" $(r=0.62 ; p=<0.01 ;$ and $r=0.63 ; p=<0.01$; respectively). The same summary variables correlated negatively with the mental component summary of SF-36 ( $r=-0.55 ; p<0.01$; and $r=-0.48 ; p=<$ 0.01 ; respectively). After the Bonferroni correction for multiple comparisons, serum CRP levels showed a positive correlation with the summary variable "fatigue impacts". However, no significant correlations were found with the ESS score (Table 3).

\section{DISCUSSION}

The present study shows that the Brazilian Portuguese-language version of the ICFS has excellent interrater/intra-rater reliability, high internal consistency, and good correlations with clinical and psychological parameters. The ICFS clearly distinguished among different patient populations.

One issue for clinicians and researchers is the choice of the fatigue scale to be used. Certainly, there is still work to be undertaken in understanding the phenomenon of fatigue and how it should be measured. The ICFS was chosen by the investigators because it is a multidimensional instrument that captures multiple characteristics and manifestations of fatigue.

In the present study, the ICFS correlated with a wide range of variables. The strong correlation between the FSS and ICFS is remarkable, considering the fact that they were developed using different samples of patients, as well as that they present different structures, layouts, and response formats.

The mental component summary of the SF-36 correlated negatively with both of the ICFS summary variables. The reason is that the SF-36 mental component summary comprises the vitality subscale, which addresses energy level and fatigue. Tang et al. (32) showed an association between SF-36 and fatigue measured by FSS. The magnitude of the correlation was highest for the vitality domain.

Both ICFS summary variables correlated with anxiety and depression. Our results are consistent with those of previous reports that showed a strong correlation between depression and fatigue. ${ }^{14,33)}$ One hallmark of depression is a decreased motivation to do things that the patient once enjoyed. This is addressed by the ICFS items (e.g., "It has been hard for me to get motivated to do my regular activities.")

Table 2. Comparisons among the three groups studied ( $N=50$ in all).

\begin{tabular}{lcccc}
\multicolumn{1}{c}{ Variable } & Group & p \\
& Control & Lung cancer & Chronic heart disease & \\
Male, $\mathrm{n}(\%)$ & $27(54)$ & $27(54)$ & $24(50)$ & 0.8 \\
Age, years & $60.5 \pm 12.2$ & $60.4 \pm 12.0$ & $60.3 \pm 12.2$ & 0.9 \\
ICFS-fatigue experiences $^{\mathrm{b}}$ & 51.6 & 80.2 & 92.2 & $0.001^{*}$ \\
ICFS-fatigue impacts $^{\mathrm{b}}$ & 47.5 & 73.7 & 103.7 & $0.001^{* *}$ \\
\hline
\end{tabular}

ICFS: Identity-Consequence Fatigue Scale. aValue is expressed as mean \pm SD. bValues are expressed as mean rank score. *Control group vs. lung cancer and chronic heart disease groups. ${ }^{*}$ Control group vs. lung cancer and chronic heart disease groups; and lung cancer group vs. chronic heart disease group. 

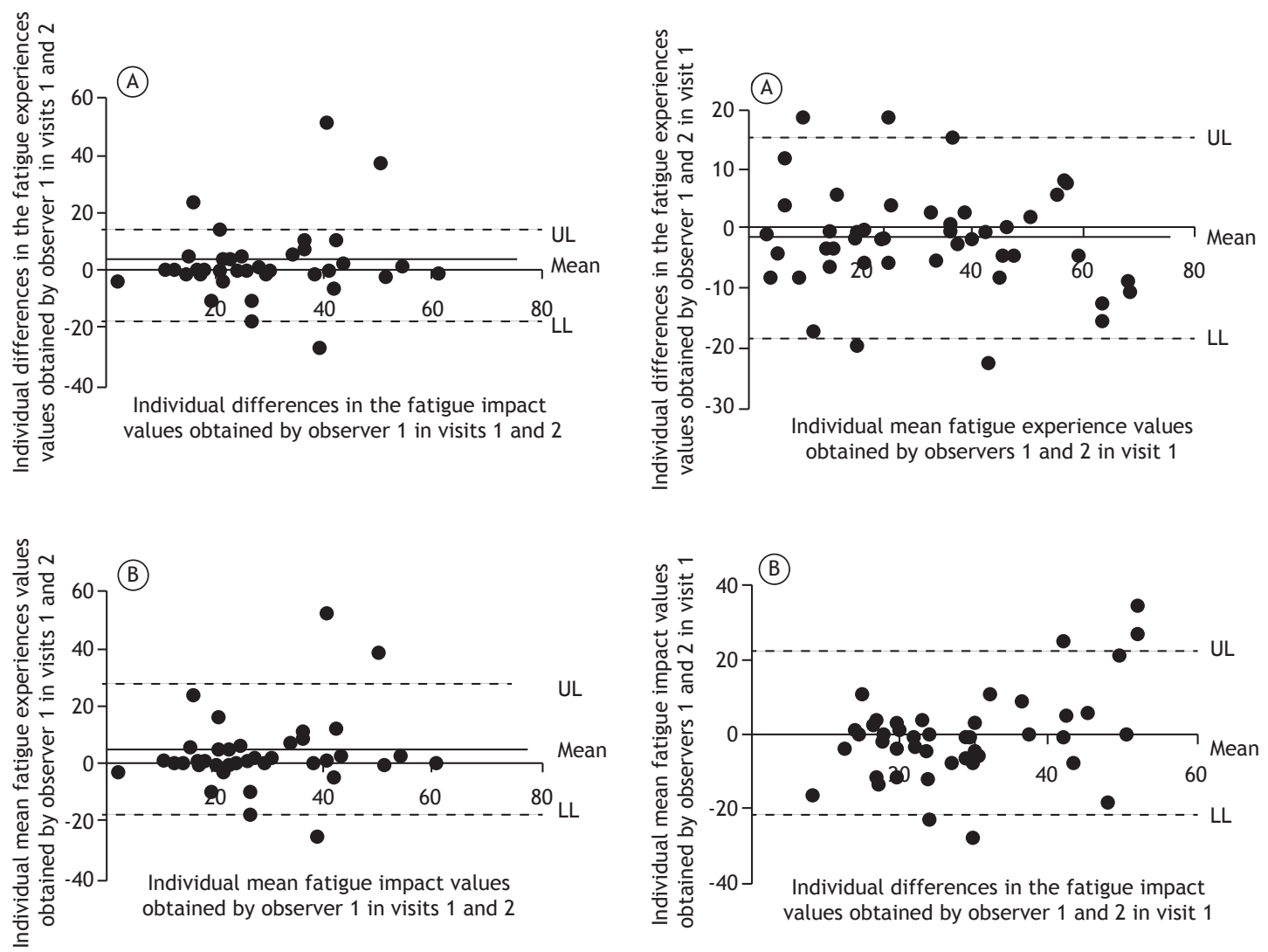

Figure 1. Bland-Altman plots. In $A$, intra-rater analysis of fatigue experiences: mean $=-0.98 ; \mathrm{UL}=15.24$; $\mathrm{LL}$ $=-17.00$. In $B$, intra-rater analysis of fatigue impacts: mean $=2.78 ; \mathrm{UL}=25.15 ; \mathrm{LL}=-19.58$. UL: upper limit; and LL: lower limit.

A remarkable correlation was found between fatigue and anxiety. This could be explained by the fact that people with anxiety are prone to panic, fear, and other high-stress responses which cause fatigue, increasing the levels of stress hormones. ${ }^{(34)}$

Previously, correlations between fatigue and sleep disorders have been noted in patients undergoing radiotherapy and surgery, as well as in those with a variety of cancer types, including LC. ${ }^{(35)}$ In our study, under the criterion of Bonferroni correction for multiple comparisons, fatigue did not correlate with excessive daytime sleepiness. A possible explanation could be the fact that only a few patients (only $10 \%$ ) presented with excessive daytime sleepiness.

We found that the presence of a systemic inflammatory response (as evidenced by elevated circulating CRP levels) was associated with increased fatigue. Some cancerous cells have been shown to secrete IL-6 and IL-8, which, in turn, induce the production of CRP. ${ }^{(36)}$ Previously, de Raaf et al. ${ }^{(37)}$ observed that fatigue dimensions were associated with inflammatory markers in different groups of cancer patients. We decided to measure CRP because it is a biomarker for which routine measurements are available in clinical practice.

Figure 2. Bland-Altman plots. In $A$, inter-rater analysis of fatigue experiences: mean $=-1.61 ; \mathrm{UL}=14.95$; and $\mathrm{LL}=-18.18$. In $\mathrm{B}$, inter-rater analysis of fatigue impacts: mean $=-0.04 ; \mathrm{UL}=22.38$; and $\mathrm{LL}=-22.46$. UL: upper limit; and LL: lower limit.

In the present study, we measured fatigue in a multidimensional way and found a correlation between CRP levels and fatigue impacts. Previous studies measured fatigue in a unidimensional way and could not find significant correlations with inflammatory markers. ${ }^{(38,39)}$ Those studies are controversial, and further research is warranted in order to investigate the relationship between elevated serum concentrations of inflammatory markers and subjective complaints of fatigue.

In contrast with our results, fatigue has been previously reported to be correlated with LC stage and the use of chemotherapy. ${ }^{(6,12)}$ Because only $12 \%$ of our patients were on chemotherapy on the assessment day, it is possible that our study lacked statistical power to detect this association. A similar effect may be present in regard to cancer staging.

Our sample of LC patients reported higher intensity of fatigue than did the control group patients. By comparing the LC group with that with another chronic disease (CHD group), we found that the scores for "fatigue experiences" were similar, although those for "fatigue impacts" were lower in the former group. Patients with heart disease present with restrictions on their activities of daily living (as measured by the 
Table 3. Correlations of fatigue, as measured by the scores of the Identity-Consequence Fatigue Scale summary variables (fatigue experiences and fatigue impacts), with other variables studied.

\begin{tabular}{lcccccc}
\multicolumn{1}{c}{ Variable } & \multicolumn{3}{c}{ Fatigue experiences } & \multicolumn{3}{c}{ Fatigue impacts } \\
& $\mathbf{r}$ & $\mathbf{p}$ & $\mathbf{p}$ & $\mathbf{r}$ & $\mathbf{p}$ & $\mathbf{p}^{*}$ \\
Fatigue Severity Scale & 0.60 & $<0.001$ & 0.007 & 0.52 & $<0.001$ & 0.007 \\
FEV, \% of predicted & 0.14 & 0.313 & 2.171 & 0.12 & 0.376 & 2.591 \\
6MWD & -0.16 & 0.261 & 1.827 & -0.09 & 0.950 & 6.651 \\
HADS-A & 0.43 & 0.002 & 0.014 & 0.62 & $<0.001$ & 0.007 \\
HADS-D & 0.60 & $<0.001$ & 0.007 & 0.63 & $<0.001$ & 0.007 \\
SF-36 MCS & -0.55 & $<0.001$ & 0.007 & -0.48 & $<0.001$ & 0.007 \\
SF-36 PCS & 0.29 & 0.239 & & 0.16 & 0.102 & 0.714 \\
Epworth Sleepiness Scale & 0.19 & 0.181 & 1.267 & 0.32 & 0.021 & 0.147 \\
CRP, mg/L & 0.28 & 0.048 & 0.336 & 0.50 & $<0.001$ & 0.007 \\
\hline
\end{tabular}

6MWD: six-minute walk distance; HADS-A: Hospital Anxiety and Depression Scale-anxiety subscale; HADS-D: Hospital Anxiety and Depression Scale-depression subscale; SF-36: Medical Outcomes Study 36-item Short-Form Health Survey; MCS: mental component summary; PCS: physical component summary; and CRP: C-reactive protein. *After Bonferroni correction: a critical $=0.048$.

summary variable "fatigue impacts"); one explanation for this could be that patients with heart disease have impaired peripheral circulatory perfusion and, consequently, reduced oxygen delivery and impaired muscle strength.

One limitation of this study is that it had a cross-sectional design; therefore, it provides no indication of the responsiveness of the ICFS over time. Another limitation is that subjects were recruited from a single center and might differ from LC patients under treatment elsewhere. Overall, more research is needed in order to understand the clinical significance attributable to patient reports of fatigue.
The strength of the study is the use of a more comprehensive measure of fatigue. The ICFS provides a general assessment for use in a variety of medical situations in which a complete evaluation of fatigue is desired. It is important to measure fatigue in LC patients in order to develop effective, patient-centered management strategies, as well as to improve the physical functioning, quality of life, and emotional/ psychological health of these patients.

In conclusion, the present study presents evidence that the Brazilian Portuguese-language version of the ICFS is a reliable tool for measuring fatigue in LC patients.

\section{REFERENCES}

1. Solano JP, Gomes B, Higginson IJ. A comparison of symptom prevalence in far advanced cancer, AIDS, heart disease, chronic obstructive pulmonary disease and renal disease. J Pain Symptom Manage. 2006;31(1):58-69. http://dx.doi.org/10.1016/j. jpainsymman.2005.06.007

2. Cella D, Davis K, Breitbart W, Curt G; Fatigue Coalition. Cancerrelated fatigue: Prevalence of proposed diagnostic criteria in a United States sample of cancer survivors. J Clin Oncol. 2001;19(14):3385 91 .

3. Hoffman $M$, Ryan JL, Figueroa-Moseley $C D$, Jean-Pierre $P$ Morrow GR. Cancer-related fatigue: The scale of the problem. Oncologist. 2007;12 Suppl 1:4-10. http://dx.doi.org/10.1634/ theoncologist.12-S1-4

4. Lawrence DP, Kupelnick B, Miller K, Devine D, Lau J. Evidence report on the occurrence, assessment, and treatment of fatigue in cance patients. J Natl Cancer Inst Monogr. 2004;(32):40-50. http://dx.doi org/10.1093/jncimonographs/lgh027

5. Forlenza M, Hall P, Lichtenstein P, Evengard B, Sullivan PF. Epidemiology of cancer-related fatigue in the Swedish twin registry. Cancer. 2005;104(9):2022-31. http://dx.doi.org/10.1002/cncr.21373

6. Curt GA, Breitbart W, Cella D, Groopman JE, Horning SJ, Itri LM et al. Impact of cancer-related fatigue on the lives of patients: new findings from the Fatigue Coalition. Oncologist. 2000;5(5):353-60 http://dx.doi.org/10.1634/theoncologist.5-5-353

7. Spathis A, Fife K, Blackhall F, Dutton S, Bahadori R, Wharton R, et al. Modafinil for the treatment of fatigue in lung cancer: results of a placebo-controlled, double-blind, randomized trial. J Clin Oncol 2014:32(18):1882-8. http://dx. doi.org/10.1200/JCO.2013.54.4346

8. Gutstein HB. The biologic basis of fatigue. Cancer 2001;92(6 Suppl):1678-83. http://dx.doi.org/10.1002/10970142(20010915)92:6+<1678::AID-CNCR1496>3.0.CO;2-R

9. Parker KP, Bliwise DL, Ribeiro M, Jain SR, Vena Cl, Kohles-Baker MK, et al. Sleep/Wake patterns of individuals with advanced cancer measured by ambulatory polysomnography. J Clin Oncol 2008;26(15):2464-72. http://dx.doi.org/10.1200/JCO.2007.12.2135

10. Cleeland CS, Bennett GJ, Dantzer R, Dougherty PM, Dunn AJ Meyers CA, et al. Are the symptoms of cancer and cancer treatment due to a shared biologic mechanism? A cytokine-immunologic model of cancer symptoms. Cancer. 2003;97(11):2919-25. http://dx.doi. org/10.1002/cncr.11382

11. Collado-Hidalgo A, Bower JE, Ganz PA, Cole SW, Irwin MR Inflammatory biomarkers for persistent fatigue in breast cance survivors. Clin Cancer Res. 2006;12(9):2759-66. http://dx.doi. org/10.1158/1078-0432.CCR-05-2398

12. Fan HG, Houédé-Tchen N, Yi QL, Chemerynsky I, Downie FP, Sabate $\mathrm{K}$, et al. Fatigue, menopausal symptoms, and cognitive function in women after adjuvant chemotherapy for breast cancer: 1- and 2-year follow-up of a prospective controlled study. J Clin Oncol 2005;23(31):8025-32. http://dx.doi.org/10.1200/JCO.2005.01.6550

13. Campos MP, Hassan BJ, Riechelmann R, Del Giglio A. Cancerrelated fatigue: a practical review. Ann Oncol. 2011;22(6):1273-9. http://dx.doi.org/10.1093/annonc/mdq458

14. Brown DJ, McMillan DC, Milroy R. The correlation between fatigue, physical function, the systemic inflammatory response, and psychological distress in patients with advanced lung cancer. Cancer. 2005;103(2):377-82. http://dx.doi.org/10.1002/cncr.20777

15. Bower JE, Ganz PA, Aziz N, Fahey JL. Fatigue and proinflammatory cytokine activity in breast cancer survivors. Psychosom Med 2002;64(4):604-11. http://dx.doi.org/10.1097/00006842-20020700000010

16. Miller $\mathrm{AH}$, Ancoli-Israel $\mathrm{S}$, Bower JE, Capuron L, Irwin MR Neuroendocrine-immune mechanisms of behavioral comorbidities in patients with cancer. J Clin Oncol. 2008;26(6):971-82. http://dx.doi. org/10.1200/JCO.2007.10.7805

17. Friedman MM, Griffin JA. Relationship of physical symptoms and physical functioning to depression in patients with heart failure. Heart 
Lung. 2001;30(2):98-104. http://dx.doi.org/10.1067/mhl.2001.114180

18. Nordgren L, Sörensen S. Symptoms experienced in the last six months of life in patients with end-stage heart failure. Eur $\mathrm{J}$ Cardiovasc Nurs. 2003;2(3):213-7. http://dx.doi.org/10.1016/S14745151(03)00059-8

19. Paddison JS, Booth RJ, Hill AG, Cameron LD Comprehensive assessment of peri-operative fatigue: development of the IdentityConsequence Fatigue Scale. Psychosom Res. 2006;60(6):615-22. http://dx.doi.org/10.1016/.jpsychores.2005.08.008

20. Paddison JS, Booth RJ, Cameron LD, Robinson E, Frizelle FA, Hill AG. Fatigue after colorectal surgery and its relationship to patient expectations. J Surg Res. 2009;15(1),145-52. http://dx.doi. org/10.1016/j.jss.2008.01.030

21. Rajmil L. Health measurement scales. A practical guide to their development and use, 3rd ed. J Epidemiol Community Health. 2005;59(3):250-1.

22. Krupp LB, LaRocca NG, Muir-Nash J, Steinberg AD. The fatigue severity scale. Application to patients with multiple sclerosis and systemic lupus erythematosis. Arch Neurol. 1989;46(10):1121-3. http://dx.doi.org/10.1001/archneur.1989.00520460115022

23. Valderramas S, Feres, AC, Melo A. Reliability and validity study of a Brazilian-Portuguese version of the fatigue severity scale in Parkinson's disease patients Arq Neuropsiquiatr. 2012;70(7):497500. http://dx.doi.org/10.1590/S0004-282X2012000700005

24. Zigmond AS, Snaith RP. The hospital anxiety and depression scale. Acta Psychiatr Scand. 1983;67(6):361-70. http://dx.doi. org/10.1111/j.1600-0447.1983.tb09716.x

25. Botega NJ, Bio MR, Zomignani MA, Garcia C Jr, Pereira WA. Mood disorders among medical in-patients: a validation study of the hospital anxiety and depression scale (HAD) [Article in Portuguese]. Rev Saude Publica. 1995;29(5):355-63.

26. Ciconelli RM, Ferraz MB, Santos W, Meinão I, Quaresma MR. Tradução para a língua portuguesa e validação do questionário genérico de avaliação de qualidade de vida SF-36 (Brasil SF-36). Rev Bras Reumatol. 1999;39(3):143-50.

27. Bertolazi AN, Fagondes SC, Hoff LS, Pedro VD, Menna Barreto SS, Johns MW. Portuguese-language version of the Epworth sleepiness scale: validation for use in Brazil. J Bras Pneumol. 2009;35(9):877-83. http://dx.doi.org/10.1590/S1806-37132009000900009

28. Johns MW. A new method for measuring daytime sleepiness: the Epworth sleepiness scale. Sleep. 1991;14(6):540-5.

29. Miller MR, Hankinson J, Brusasco V, Burgos F, Casaburi R, Coates A, et al. Standardisation of spirometry. Eur Respir J. 2005;26(2):319-38. http://dx.doi.org/10.1183/09031936.05.00034805

30. Pereira CA, Sato T, Rodrigues SC. New reference values for forced spirometry in white adults in Brazil. J Bras Pneumol. 2007;33(4):397406. http://dx.doi.org/10.1590/\$1806-37132007000400008

31. ATS Committee on Proficiency Standards for Clinical Pulmonary Function Laboratories. ATS statement: guidelines for the six-minute walk test. Am J Respir Crit Care Med. 2002;166(1):111-7. http:// dx.doi.org/10.1164/ajrccm.166.1.at1102

32. Tang WK, Lu JY, Chen YK, Mok VC, Ungvari GS, Wong KS. Is fatigue associated with short-term health-related quality of life in stroke? Arch Phys Med Rehabil. 2010;91(10):1511-5. http://dx.doi. org/10.1016/.apmr.2010.06.026

33. Stone $P$, Richards $M, A^{\prime}$ Hern $R$, Hardy J. Fatigue in patients with cancers of the breast or prostate undergoing radical radiotherapy. J Pain Symptom Manage. 2001;22(6):1007-15. http://dx.doi. org/10.1016/S0885-3924(01)00361-X

34. Ryan JL, Carroll JK, Ryan EP, Mustian KM, Fiscella K, Morrow GR Mechanisms of cancer-related fatigue. Oncologist. 2007;12 Suppl 1:22-34. http://dx.doi.org/10.1634/theoncologist.12-S1-22

35. Roscoe JA, Kaufman ME, Matteson-Rusby SE, Palesh OG, Ryan $\mathrm{JL}$, Kohli $\mathrm{S}$, et al. Cancer-related fatigue and sleep disorders. Oncologist. 2007;12 Suppl 1:35-42. http://dx.doi.org/10.1634/ theoncologist.12-S1-35

36. Heikkilä K, Ebrahim S, Lawlor DA. A systematic review of the association between circulating concentrations of $C$ reactive protein and cancer. J Epidemiol Community Health. 2007;61(9):824-33. http://dx.doi.org/10.1136/jech.2006.051292

37. de Raaf PJ, Sleijfer S, Lamers CH, Jager A, Gratama JW, van de Rijt CC. Inflammation and fatigue dimensions in advanced cancer patients and cancer survivors: an explorative study. Cancer. 2012;118(23):6005-11. http://dx.doi.org/10.1002/cncr.27613

38. Rich $T$, Innominato PF, Boerner J, Mormont MC, lacobelli S, Baron $\mathrm{B}$, et al. Elevated serum cytokines correlated with altered behavior serum cortisol rhythm, and dampened 24-hour rest-activity patterns in patients with metastatic colorectal cancer. Clin Cancer Res. 2005;11(5):1757-64. http://dx.doi.org/10.1158/1078-0432.CCR-042000

39. Laird BJ, Scott AC, Colvin LA, McKeon AL, Murray GD, Fearon KC, et al. Pain, depression, and fatigue as a symptom cluster in advanced cancer. J Pain Symptom Manage. 2011;42(1):1-11. http://dx.doi. org/10.1016/j.jpainsymman.2010.10.261 